\title{
Complete Chloroplast Genome of Calligonum Mongolicum: Genome Organization, Codon Usage Pattern, Phylogenetic Relationships, Comparative Structure and Adaptive Evolution Analysis
}

\section{Huirong Duan}

Chinese Academy of Agricultural Sciences Lanzhou Institute of Husbandry and Pharmaceutical Sciences

\section{Qian Zhang}

Chinese Academy of Agricultural Sciences Lanzhou Institute of Husbandry and Pharmaceutical Sciences

\section{Hongshan Yang}

Chinese Academy of Agricultural Sciences Lanzhou Institute of Husbandry and Pharmaceutical

Sciences

\section{Fuping Tian}

Chinese Academy of Agricultural Sciences Lanzhou Institute of Husbandry and Pharmaceutical

Sciences

\section{Yu Hu}

Chinese Academy of Agricultural Sciences Lanzhou Institute of Husbandry and Pharmaceutical Sciences

\section{Chunmei Wang}

Chinese Academy of Agricultural Sciences Lanzhou Institute of Husbandry and Pharmaceutical Sciences

\section{Yuan Lu}

Chinese Academy of Agricultural Sciences Lanzhou Institute of Husbandry and Pharmaceutical Sciences

\section{Huijun Yuan}

Lanzhou University of Technology

\section{Guangxin Cui ( $\nabla$ cuigx03@sina.com )}

Chinese Academy of Agricultural Sciences Lanzhou Institute of Husbandry and Pharmaceutical Sciences 
Keywords: Calligonum mongolicum, Chloroplast genome, Synonymous codon usage, Genomic structure, Phylogeny

Posted Date: September 1st, 2020

DOI: https://doi.org/10.21203/rs.3.rs-49271/v1

License: (c) (i) This work is licensed under a Creative Commons Attribution 4.0 International License. Read Full License 


\section{Abstract}

Background The perennial shrub of Calligonum mongolicum is a dominant native plant in all Calligonum species, which has the largest and most widespread geographic distribution in arid deserts of northern China. Understanding the phylogenetic relationship between $C$. mongolicum and closely related plant species will offer guidance on the classification and identification of inter-species and their varieties. The chloroplast (cp) genome is an optimal model to decipher phylogenetic relationships and genome evolution in related plant families. In the present study, the complete $\mathrm{cp}$ genome of $C$. mongolicum was sequenced, and the characteristics were described, then the genomic structure was compared to other three Polygonaceae species.

Results The cp genome of $C$. mongolicum was 162,124 bp in length with a quadripartite structure. A total of 131 functional genes were annotated, 14 different genes of which harbored introns and exons, 50 long repeat sequences and 244 simple sequences repeats were identified. Synonymous codon usage (SCU) analysis exhibited A/T preference, and 7 codons were identified as the optimal codons. Multivariate statistical analysis of parity rule 2, ENC-plot, and neutrality plot were combined conducted to imply natural selection as the crucial constraint in SCU bias in $C$. mongolicum cp genome.The phylogenetic tree showed that Rumex acetosa was the most related plant to $C$. mongolicum. From the comparative analysis of genomic structures, the inverted repeat regions (IRa and IRb) were less divergent than other parts and coding regions was relatively conserved than non-coding regions. Compared to other species in the Polygonaceae, the borders of IRb/SSC and SSC/IRa in C. mongolicum changed greatly. Furthermore, adaptive evolution analysis of 75 orthologous protein-coding genes indicated that only the $p s b K$ gene was under positive selection, which might be crucial in the adaptive evolution of $C$. mongolicum.

Conclusions Our results comprehensively depicts the architecture of $C$. mongolicum cp genome, and will lay a vigorous foundation for further study on molecular marker selection, phylogenetic analysis, and population researches in Calligonum species.

\section{Background}

Calligonum $\mathrm{L}$. belonging to the family Polygonaceae, contains approximately 35 species of perennial xerophytic shrubs or subshrubs, are successful pioneer plants for desert vegetation succession, and distribute in northern Africa, Southern Europe and Asia [1, 2]. There are 24 Calligonum species in China and almost of which possess significant ecological values [3]. The Calligonum species are divided into four groups according to the surface appendage of the achene [4, 5]. Calligonum mongolicum, belonging to Sect. Medusa Sosk. et Alexandr., has the largest and most widespread geographic distribution in arid deserts of northern China of all Calligonum species [6]. As a perennial shrub, $C$. mongolicum is native dominant in active sand dunes, exhibits strong resistance of drought, salt-alkali, high temperature, barren soil, wind erosion, also propagation strategies through sexual and asexual ways, thus it is often used for vegetation restoration in the desert $[7,8]$. In recent years, the population of $C$. mongolicum exhibits a fast expansion tendency in mobile sand dunes of the Minqin Desert [9]. Actually, the surface appendages of 
the achene from $C$. mongolicum and $C$. roborovskii have similar characteristics, and the geographical distributions of $C$. mongolicum and $C$. roborovskii are overlapped to some certain areas, as a result causing difficulty in identifying $C$. mongolicum [10]. Understanding the phylogenetic relationship between C. mongolicum and closely related plant species will offer guidance on the classification and identification of inter-species and their varieties.

Phylogenetic relationships are revolutionarily and frequently analyzed by genome sequencing, including the chloroplast genome (cp genome), the mitochondrion genome, and nucleus genome [11, 12]. The complete $\mathrm{cp}$ genome, which possesses many characteristics of small size, simple and highly conserved structure, single parentalin heritance, and haploid nature, is widely applied for species identification, phylogenic analysis, and adaptive evolution analysis [13]. Huang et al. [14] sequenced the complete $\mathrm{cp}$ genomes of five Dilciptera species, and compared the interspecies relationships of the five species. Xue et al. [12] also finished the cp genome comparison of three economic trees from Prunus, found the genomic structure difference, revealed the possible molecular markers, and concluded the phylogenetic evolution relationships. Until now, studies on the cp genome sequences have been conducted in many plant species, for example, watercress, yellow mustard, Echinacanthus attenuatus, and so on [15-17]. Thus, the $\mathrm{cp}$ genome is an optimal model to decipher phylogenetic relationships and genome evolution in related plants families.

Chloroplasts is a photosynthetic organelle in plant cells that plays crucial roles in the photosynthesis and crucial metabolites biosynthesis, for example amino acids, starch, fatty acids and pigments [18]. In general, the length of the $\mathrm{cp}$ genome ranges from 120-160 kb, the difference of which is mainly due to inverted repeated regions (IR) expansion, contraction or loss [19]. The cp genome encodes 63-209 unique genes, and is conserved with quadripartite organizations including a pair of IR regions (IRa and $\mathrm{IRb})$, a large single copy (LSC) region and a small single copy (SSC) region [20]. For majority of higher plants, chloroplast is highly conservative in genes number, arrangement order and function [21]. However, gene losses and genome rearrangement can be found in some leguminous plants and conifer algae [22, 23]. After the first cp genome data of tobacco published in 1986, more and more plant cp genomes are completed sequencing, yet none of species from Calligonum $\mathrm{L}$. has obtained the complete $\mathrm{cp}$ genomes data [24].

In the current study, the $\mathrm{cp}$ genome of $C$. mongolicum was constructed firstly by using Illumina sequencing and integrating a combination of de novo sequencing and reference-guided assembly. Then, the whole cp genome characteristics of $C$. mongolicum were described, and the synonymous codon usage (SCU) pattern, simple sequence repeats (SSRs) and long repeats were analyzed. Besides, we compared the cp genome of $C$. mongolicum with the published cp genomes of other three related species, including genome structure, IR contraction and expansion, and selective pressure events. This study may provide positive clues for adaptive evolution analysis of the Calligonum species.

\section{Materials And Methods}




\section{Materials}

The wild seedlings of $C$. mongolicum were transplanted from the Minqin desert to Lanzhou Scientific Observation and Experiment Field Station of the Ministry of Agriculture for Ecological System in the Loess Plateau Area $\left(36^{\circ} 01^{\prime} \mathrm{N}, 103^{\circ} 45^{\prime} \mathrm{E}\right.$, altitude $\left.1700 \mathrm{~m}\right)$, Gansu, China in 15 May 2019. The station was belonged to Lanzhou Institute of Husbandry and Pharmaceutical Science, Chinese Academy of Agricultural Sciences, and we were approved to perform plant species planting and cultivating. $C$. mongolicum is a common wild plant in the Minqin desert, thus collecting or transplanting it for scientific research is not restricted in Ganu Province. Fresh leaf samples of $C$. mongolicum were collected in 22 July 2019. The sample collecting procedure was complied with our institutional guidelines. The voucher specimen was identified formally by expert on plant taxonomy from Gansu Grass Variety Committee and kept in Herbarium of Lanzhou Institute of Husbandry and Pharmaceutial Science (CYSLSCmZhang20190722). Samples were quickly frozen in liquid nitrogen and conserved in $-80^{\circ} \mathrm{C}$ for the subsequent analysis.

\section{DNA Extraction, Illumina Sequencing, Assembly and Annotation}

Genomic DNA was isolated by the Plant Genomic DNA Rapid Extraction Kit (Biomed Gene Technology) with the modified CTAB method [25]. 1\% Agarose gel electrophoresis and Qubit Fluorometer (Invitrogen) were used to check DNA integrity and quality. One library (350 bp) was constructed by using pure DNA with the NEBNext ${ }^{\circledR} U$ Itra $^{\text {TM }}$ DNA Library Prep Kit for Illumina ${ }^{\circledR}$. The library was sequenced with an Illumina NovaSeq platform (Beganen Tech Solution CO., Ltd, Wuhan, China) and finally 150 bp paired-end reads were generated. The unknown reads and low-quality reads were filtered using SOAPnuke software (version: 1.3.0). Chloroplast-like reads were identified by BLAST (E-value $\leq 1^{\mathrm{e}^{-5}}$ ) with other related species. Finally, the chloroplast-like reads were assembled using NOVOPlasty (version: 32 ) with the parameter of k-mer 39 to form a circular genome. The sequences were annotated using GeSeq, mainly containing coding gene prediction and non-coding RNAs annotation (rRNA and tRNA) [26]. The circular genome map of $C$. mongolicum was drawn through the OGDRAWv1.2 program [27].

\section{Synonymous Codon Usage Bias Analysis}

A number of the codon usage indicators were performed via the program codon W version 1.3 (https://sourceforge.net/projects/codonw/), including the relative synonymous codon usage value (RSCU), the effective number of codons (ENC), $G+C$ content of the gene (GC), the frequency of the nucleotides $\mathrm{G}+\mathrm{C}$ at the 3 rd position of synonymous codons $\left(\mathrm{GC}_{3 \mathrm{~s}}\right)$, and the base compositions $\left(\mathrm{A}_{3 \mathrm{~s}}, \mathrm{~T}_{3 \mathrm{~s}}\right.$, $\mathrm{G}_{3 \mathrm{~s}}$, and $\mathrm{C}_{3 \mathrm{~s}}$ ) [28]. The RSCU value and ENC value were used together to describe codon usage patterns [29]. The $\mathrm{G}+\mathrm{C}$ content at the $1 \mathrm{st}, 2 \mathrm{nd}$, 3rd of codons $\left(\mathrm{GC}_{1}, \mathrm{GC}_{2}, \mathrm{GC}_{3}\right)$ and the average $\mathrm{GC}$ content of the 1st and $2 \mathrm{nd}\left(\mathrm{GC}_{12}\right)$ were calculated by Cusp function from EMBOSS (http://imed.med.ucm.es/EMBOSS/) [30]. Synonymous codons with RSCU values $>1.3$ were identified as high frequency codons. The optimal codon of the gene was speculated as the codon with both the highest RSCU value and the largest $\triangle \mathrm{RSCU}$ 
[31]. Parity rule 2 (PR2) plot mapping analysis was constructed to show the relationship of the values $\mathrm{A}_{3}$ / $\left(A_{3}+T_{3}\right)$ and $G_{3} /\left(G_{3}+C_{3}\right)$, and the data were distributed into four quadrants in a scatter diagram [32]. ENC-plot mapping analysis was performed to reflect the relationship of the ENC values against the $\mathrm{GC}_{3 S}$ values [33]. Neutrality plot mapping analysis was used to analyze the relationship of the $\mathrm{GC}_{12}$ values and $\mathrm{GC}_{3}$ values of all the genes [34].

\section{Long repeat sequences and SSRs analysis}

Long repeats including forward repeats and reverse repeats were analyzed by REPuter (http://bibiserv.techfak.uni-bielefeld.de/reputer) [30]. The hamming distance was set to 0 and the minimal repeat size was $20 \mathrm{bp}$. The SSRs were analyzed through the Perl script MISA (version: 1.0), and the SSRs parameters were defined as follows, the threshold of mononucleotide SSRs was ten repeats, the thresholds of dinucleotide and hexanucleotide SSRs were five repeats [35].

\section{Phylogenetic Analysis}

Phylogenetic tree with the bootstrap replicates set to 1000 was constructed by neighbor joining (NJ) analysis through TreesBeST (Version: 1.9.2, http://www.mybiosoftware.com/treebest-1-9-2-softwaresphylogenetic-trees.html). The $\mathrm{cp}$ genomes of $C$. mongolicum and other 36 species were used to investigate the evolution of $C$. mongolicum. The $\mathrm{cp}$ genomes information of the 36 plant species were downloaded from NCBI database.

\section{Genome Structure Comparison}

Based on the above results of the phylogenetic analysis, the complete cp genome of $C$. mongolicum was compared with other three closely related species of Rumex acetosa (NC_042390.1), Rheum palmatum (NC_027728.1), and Fagopyrum esculentum (NC_010776.1) using the mVista program with the shuffleLAGAN mode [36]. The annotation of $C$. mongolicum was used as reference. The IRscope tool was used to visualize the genes on the boundaries of the junction sites of these four closely related species [37].

\section{Selective pressure analysis}

The orthologous genes of the Polygonaceae family were identified by OrthoMCL [38]. The sequences alignment of each orthologous gene was conducted using MAFFT [39]. The non-synonymous substitution rate $\left(\mathrm{K}_{\mathrm{A}}\right)$ and synonymous substitution rate $\left(\mathrm{K}_{S}\right)$ were calculated by PAML [40]. The $\omega$ value was the ratio of $\mathrm{K}_{\mathrm{A}} / \mathrm{K}_{\mathrm{S}}$.

\section{Results}

\section{Features of C. mongolicum Cp Genome}

The cp genome of C. mongolicum was 162,124 bp in length, was comprised by a pair of IR regions (IRa and IRb) (30,512 bp), a large single copy (LSC) region of $87,718 \mathrm{bp}$ and a small single copy (SSC) region 
of 13,382 bp (Fig. 1). The nucleotide composition of C. mongolicum cp genome was enriched in A/T nucleotides. The A + T content of the cp genome were $62.5 \%$, which was significantly higher than the overall $\mathrm{G}+\mathrm{C}$ content. The $\mathrm{A}+\mathrm{T}$ content of the IR regions were $58.66 \%$, obviously lower than LSC and SSC regions $(64.42 \%$ and $67.51 \%$, respectively) (Table 1$)$. Weak base composition asymmetry (A-T, C-G) was found in C. mongolicum cp genome.

The positions of the 131 functional genes annotated in C. mongolicum cp genome were shown in Fig. 1. 78 genes were protein-coding genes, accounting for the half portion (59.5\%) of the total genes. The remaining genes included 45 tRNA genes and 8 rRNA genes. According to the different functions, all the annotated genes were classified into four classes, including photosynthesis, self-replication, biosynthesis, and unknown functions (Table S1). Seventeen genes were duplicated in the IR regions, harboring 6 protein coding genes, 4 rRNA genes, and 6 tRNA genes.

In C. mongolicum cp genome, 12 different genes possessed a single intron and two exons, containing 5 tRNA genes and 7 protein coding genes, whereas the protein coding gene of ycf 3 and clpP had two introns and three exons (Table 2). Of the total intron-containing genes, the gene of trnK-UUU had the largest intron (2511 bp), and the trnL-UAA had the smallest intron (520 bp).

\section{Synonymous Codon Usage Analysis}

A total of 51 coding sequences (CDSs) with length longer than $300 \mathrm{bp}$ were screened for synonymous codon usage (SCU) bias analysis. In general, the four nucleotides were unevenly represented in the 51 CDSs. Adenine (A) and thymine ( $T$ ) were the most represented ( $43.3 \%$ and $46.4 \%$, respectively), cytosine (C) and guanine (G) were the least represented (16.7\% and $16.9 \%$, respectively), The average GC content of the CDSs was $38.7 \%$. We identified the total of 61 synonymous codons except for stop codons, among which, the total of 18 codons with RSCU value more than 1.3 was identified as high frequency synonymous codons, 29 codons with $\triangle R S C U$ value more than 0.08 were identified as the high expressed codons (Table 3 and Table S2). 7 codons with high frequency as well as high expression including TTT, GGA, CAT, AAA, TTA, AAT and CCT were identified as the optimal codons.

To further analyze the SCU pattern in C. mongolicum cp genome, multivariate statistical analysis of PR2, ENC-plot analysis, and neutrality plot were combined conducted. PR2 plot mapping showed that the genes distributed unevenly in the four quadrants centered on 0.5 , most points located under the horizontal centered line of 0.5 (the ratio of $\left.A_{3} /\left(A_{3}+T_{3}\right)<0.5\right)$ (Fig. 2a). ENC plot was used to analyze the codon usage variation of the $51 \mathrm{CDSs}$ (Fig. 2b). A majority of the points were lying away from the expected curve, accompanied with a relative concentrate distribution, and except for some points (rp116, ycf2, ycf3, and so on) located on the curve. Besides, we performed neutrality plot analysis to reveal the relationship of $\mathrm{GC}_{12}$ and $\mathrm{GC}_{3}$ (Fig. 2c). Only one gene of ycf2 located on the effected curve, the remaining genes were up the standard curve.

\section{Long-Repeat Sequences and Simple Sequences Repeats (SSRs) Analysis}


The long repeat sequences in C. mongolicum cp genome were searched by REPuter software. A total of 50 long repeats were detected, 44 were forward and 6 were reverse repeats (Table 4). A majority long repeat sequences were only located in intergenic spaces (IGSs) (47\%), 39\% long repeat sequences were distributed in different genes, and the remaining long repeats (14\%) were detected both in IGSs and genes. It was worth noting that the six reverse repeats were all located in IGSs. Besides, a total of 17, 1 , 12 , and 10 repeats harbored only one region of LSC, SSC, IRa and IRb regions, respectively. Another 10 repeats were detected simultaneously in two regions. Ycf1 CDS possessed the highest number of long repeats (14) and the longest repeats at $45 \mathrm{bp}$.

A total of 244 SSRs were found in C. mongolicum cp genome using MISA perl script. Among the identified SSRs, $67.2 \%$ was located in the LSC regions, $23.0 \%$ and $9.8 \%$ were found in the IR and SSC regions, respectively (Fig. 3a). 158 SSRs were located in IGSs, 80 SSRs were found in the coding regions and only 6 were found in introns (Fig. 3b). The numbers of mono-, di-, tri-, and tetranucleotides were 147, 43,4 , and 7, respectively (Fig. 3c). Mononucleotide repeats were the most frequented, accounting for $60.2 \%$ of the total repeats, while dinucleotides repeats accounted for $17.6 \%$, and other SSRs were less common. Among all the identified SSRs, 20 SSRs belonged to G/C types, and the remaining SSRs belonged to the $A / T$ types.

\section{Phylogenetic Analysis}

The phylogenetic tree was constructed based on a multiple alignment of nucleotide sequences of complete cp genomes from 37 plant species (Fig. 4). Drosera rotundifolia was used as the outgroup. The results showed that the species in the Polygonaceae family formed a clade, $\mathrm{C}$. mongolicum was clustered closely to R. acetosa, R. palmatum, Oxyria sinensis, and F. esculentum. Furthermore, R. acetosa was the most related plant to $\mathrm{C}$. mongolicum.

\section{Comparative Analysis of Genomic Structure}

The cp genome of $C$. mongolicum was compared to its closely related species including $R$. acetosa, $R$. palmatum, and F. esculentum (Table 5). C. mongolicum had the largest $\mathrm{cp}$ genome size, the largest SSC region and the most tRNA genes. $F$. esculentum had the smallest $\mathrm{cp}$ genome size and the largest LSC region. To further verify the genome divergence among these four species, sequence identity was compared using mVISTA with $C$. mongolicum as a reference (Fig. 5). Generally, IR regions were relatively conserved, while LSC and SSC regions were more divergent. Higher divergence of conserved non-coding regions were found than coding regions, for example, the IGS regions of rps 16 and tmQ-UUG, ycf3 and tmS-GGA. Besides, significant differences were found in the regions of coding genes (petD and $n d h A$ ) and non-coding RNAs (tml-GAU).

\section{IR Contraction and Expansion}

The LSC/IR and SSC/IR boundaries of the cp genomes of $C$. mongolicum and other three related plant species were compared (Fig. 6). Six different genes were located at the juncture of the LSC/IRb (rps19 
and $r p 12), \mathrm{IRb} / \mathrm{SSC}(\mathrm{ndhF}), \mathrm{SSC} / \mathrm{IRa}$ (rps15 and $y c f 1)$, and IRa/LSC borders (rp12 and $t r n H$ ), respectively. The $n d h F$ gene crossed the IRb/SSC border, with 62-95 bp lengths within IRb region. Compared to other species in the Polygonaceae, the borders of the IRb/SSC and SSC/Ira in C. mongolicum changed greatly. The LSC/IRb and IRa/LSC borders were relatively conserved in C. mongolicum, R. palmatum, and $F$. esculentum, however the rps19 gene at the LSC/IRb border and the trnH gene at the IRa/LSC border in $R$. acetosa varied from the other three species.

\section{Selective pressure events}

A total of 75 orthologous protein-coding genes were found in the family of Polygonaceae. The $\omega$ values of most genes were lower than 1, except for the psbK gene found in the LSC region, which had a $\omega$ value of 1.0556 (Figure 7). The $\omega$ values of some genes were 0 , such as psbl, petN, ycf3, psbE, petG, rps12, and ndhE.

\section{Discussion}

\section{Features of the C. mongolicum Cp Genome}

Cp genomes of land plants are mostly conserved in structures, gene content, and organization of content [41]. Generally, the cp genome is a typical quadripartite circular structure and composed by two IR regions, large (LSC) and small single-copy (SSC) regions [42]. However, Tao et al. [21] reported alfalfa had a special $\mathrm{cp}$ genome structure with only one IR region. Besides, the linear $\mathrm{cp}$ genome is existed which is different from the typical plant cp genomes with a single circular molecule [43]. In this study, the complete $\mathrm{cp}$ genome of $\mathrm{C}$. mongolicum revealed a typical circular and quadripartite structure, implying the relatively conserved $\mathrm{cp}$ genome in land plants. Despite the structures of $\mathrm{cp}$ genomes in different plant species are overall conserved, the size of which varies from $107 \mathrm{~kb}$ to218 kb [19]. The cp genome of $\mathrm{C}$. mongolicum was $\sim 162 \mathrm{~kb}$, longer than the closely related plant species of R. acetosa ( 160 kb), R. palmatum $(\sim 161 \mathrm{~kb})$, and F. esculentum( $159 \mathrm{~kb})$ to a certain extent. We also found that the $A+T$ contents of the IR regions were significantly lower than other regions, which was similar to the observations in Prunus species, Quercus acutissima, and Phleum pretense and so on [14, 42, 44].

In land plant cp genomes, gene and intron content are highly conserved, although losses of them have been found in many angiosperms [11]. Funk et al. [45] found the losses of ndh genes in Cuscuta reflexa, they speculated the genes might be transferred to nuclear or the genes did not part in the critical life development. Here, we analyzed the genes and intron contents in C. mongolicum cp genome. The $\mathrm{cp}$ genome of $\mathrm{C}$. mongolicum exhibited a complete set of genes (131), suggesting these genes might be critical to its development. Our results were similar to the finding of 130 genes in Nelumbo nucifera cp genome [46]. The cp genomes of the earliest diverging angiosperms contain the complete repertoire of 18 genes with introns [11]. Additionally, in many plants, the loss phenomenon of introns within proteincoding genes is often occurred, for example, Cicer arietinum, Mahonia bealei, and Hordeum vulgare [4749]. The proteins encoded by genes with intron loss possess diverse functions. In C. mongolicum cp genome, we searched a total of 14 different genes with intron, and 4 intron losses were found, including 
ycf1, rpoC2, rps19, and ndhF. The genes with intron losses might endow C. mongolicum diverse functions on RNA polymerase, ribosomal proteins, and NADH dehydrogenase.

\section{Synonymous Codon Usage Pattern}

SCU bias reflects uneven usage of synonymous codons with the same amino acid, which is different among different species and genes [50]. The possible causes of SCU bias have been investigated in the genomes of numerous living organisms, for example, Zea mays, cotton, Arabidopsis and so on [51-53]. In this study, $51 \mathrm{CDSs}$ of $C$. mongolicum cp genome were selected to analyze the SCU bias. AT/GC nucleotide usage differed among the three positions of codon, and the genes showed a preference for ATending codons, thus revealing a SCU imbalance of $A / T$ and G/C at the third base position. This speculation was further confirmed by PR2 analysis. The similar observations were also found in Elaeagnus angustifolia, Porphyra umbilicalis and so on [17, 54].

In the case of random mutation or mutation pressure in a certain direction, there should be no change in the three different positions of each codon and the base content should be similar [31]. Thus, the preference for $\mathrm{A} / \mathrm{T}$ ending bases would drive the observation of natural selection competing against mutation pressure. In order to analyze the two major evolutionary factors on codon usage in $C$. mongolicum, we constructed ENC plot analysis and neutrality plot analysis. ENC plot analysis reflects the relationship of ENC value and $\mathrm{GC}_{3 s}$, thus detecting the $\mathrm{SCU}$ variation among the genes [33]. The distribution comparison of genes and the standard curve could be indicative for some other factors except mutation pressure [33]. In our study, it was observed that a few genes were lying on the curve, which definitely originated from the extreme mutation pressure. However, a majority of the points were lying well below the curve, suggesting that a majority of genes in $C$. mongolicum $\mathrm{cp}$ genome had other SCU bias, for example natural selection. This hypothesis was largely supported by neutrality plot mapping analysis. Neutrality plot analysis is useful to compare the impacts of selection constraints and mutation on SCU [55]. The low correlation between $\mathrm{GC}_{12}$ and $\mathrm{GC}_{3}$ shows that the base composition of the 3 positions are different, and the GC content of the $\mathrm{cp}$ genome is highly conserved, indicating that natural selection is the most important determinant of codon usage patterns [56]. In the present neutral graph, no correlation was found between $\mathrm{GC}_{3}$ and $\mathrm{GC}_{12}$, indicating strong difference appeared, and natural selection would be crucial for SCU bias in $C$. mongolicum cp genome.

\section{Molecular Markers}

Long repeat sequences are associated with the sequence divergence and rearrangement of the $\mathrm{cp}$ genomes for illogical recombination and slipped-strand mismatch [57]. In C. mongolicum cp genome, more long repeats were found in LSC region than in IRs and SSC regions, verifying an uneven distribution phenomenon of long repeats in $\mathrm{cp}$ genomes. Many studies indicate that the sequence divergences are higher in the LSC and SSC regions than IR regions, also higher in IGSs than coding regions [58, 59]. Thus, the long repeats appeared in LSC and SSC regions, such as ycf3, ndhA, psaA and psaB, might help reducing sequence mutations in these regions. For the abundant variable sites, the gene of ycf 1 was been 
reported to be used in DNA barcodes [60]. Huang et al. [14] recommended ycf1 could be used as a candidate molecular marker for the Diciptera species. Similar to the finding in Dicliptera species, ycf1 harbored the highest number and the longest length of long repeats in C. mongolicum cp genome, thus we speculated ycf1 might be used as an important molecular marker for phylogenetic elucidation in Calligonum species.

SSRs, known as microsatellites, have many forms in the cp genome, and the variations in SSRs copy numbers are different between plant species [61, 62]. SSRs are usually used as potential genetic markers for plant population genetics, polymorphism investigations, and evolutionary research $[16,63]$. Different to the nuclear genome, SSR variations in the cp genome exhibit outstanding characteristics in evolutionary study since it is sensitive to population genetic effects and exploration the maternal gene flow of populations [64]. In the present study, the SSRs identified in C. mongolicum cp genome were inclined to $A / T$ types, which were similar to the observations in three Prunus species and Nasturtium officinale $[12,15]$, supporting the supposition that cp SSRs are generally composed by poly-adenine/thymine (polyA/T) repeats [42]. Similar to long repeats, morenumbers of SSRs in LSC region than IRs and SSC region also implied an imbalanced repeats distribution in the cp genomes. Besides, the presence of the SSRs is indicators of important hotspots for genome recombination [14]. SSRs in C. mongolicum cp genome mainly located in IGSs which possessed high variable feature in the cp genome, suggesting that these regions could be treated as mutational hotspots. All the long repeats and SSRs identified in this study might furnish more venues for potential genetic markers in species identification and phylogenetic researches of Calligonum species.

\section{Phylogenetic Analysis and Genomic Structure Comparison}

Cp genome displays vast phylogenetic information, is usually used for phylogenetic reconstruction and population studies $[65,66]$. In order to explore the phylogeny location of $C$. mongolicum and clearly elucidatethe genetic evolutionary relationships within Polygonaceae, we performed phylogenetic analysis based on the $\mathrm{cp}$ genome of $\mathrm{C}$. mongolicum and other $36 \mathrm{cp}$ genomes data of plant species. From the phylogenetic tree, all the 5 studied Polygonaceae species were clustered together, and C. mongolicum was accommodated as the neighbouring clade to the branch of R. acetosa accompanied with a $100 \%$ bootstrap value, fully confirming the genus Calligonum as a member of Polygonaceae. Thus, the constructed phylogenetic tree could be useful to confirm the phylogenetic position of $\mathrm{C}$. mongolicum and further understanding the phylogeny relationships among more Polygonaceae species in the future.

Although cp genomes have highly conserved structures of most plants, four regions have varied genome sizes $[49,67]$. The genomic structure comparison of four Polygonaceae species including C. mongolicum showed that they possessed different sizes in the four regions, mainly due to their different genus classifications. Among the four cp genomes of Polygonaceae species, more divergences emerged in LSC region, and higher divergence of conserved non-coding regions were found than coding regions. Our results were similar to the reports in other angiosperms, for example, Kaempferia galangal [68] and four Echinacanthus species [17], implying that less divergence in the IR regions and coding regions possibly 
might cause copy corrections in the process of gene conversion. Besides, as the most conserved regions, frequent expansions and contractions at the boundaries of SSC/IR and LSC/IR can reflect the taxa relationships, thereby recognizing as evolutionary signals [69]. Compared to C. mongolicum cp genome, the IR regions of $R$. acetosa $c p$ genome exhibited a slight contraction, and to the contrary, in $F$. esculentum and R. palmatum exhibited a slight expansion. Thus, the contractions and expansions at the two boundaries would contribute to the size variations of the four Polygonaceae species cp genomes.

\section{Adaptive evolution analysis}

Adaptability improvement of a species during evolutionary progress is reflected by adaptive evolution [14]. Adaptive evolution, driven by evolutionary factors (for instance natural selection), leads to pressures and diversity at different biological organization processes [70]. Makalowski and Boguski [71] reported that the $\omega$ value had been widely applied to identify the evolutionary dynamics and explore adaptive characteristics among species. The gene is under positive selection when the $\omega$ value is more than 1 . Otherwise, the gene is negatively selected. The positively selected genes play important roles in diverse environment adaptation [17]. In the present study, the $\omega$ value of psbK gene was more than 1 , suggesting psbK was under positive selection. Similar to our result, psbK was also detected under positive selection in karst topography [17]. Thus, we speculated the gene psbK could play an important role in the adaptation evolutionary process of Polygonaceae species to the diverse environment, and its unique function needs to be validated in further study.

\section{Conclusions}

In the study, the complete $\mathrm{cp}$ genome of $C$. mongolicum was firstly depicted comprehensively, including genome features, SCU bias, identification of long-repeat sequence and SSRs, and adaptation evolution analysis. The $\mathrm{cp}$ genome of $C$. mongolicum was a typical quadripartite structure and 131 functional genes were annotated, while 4 intron losses including ycf1, rpoC2, rps 19 , and $n d h F$ were found. Codons in C. mongolicum $\mathrm{cp}$ genome presented $\mathrm{A} / \mathrm{T}$ ending preference, possibly caused by major natural selection constraints. The phylogenetic analysis among 37 species revealed $C$. mongolicum was closely related to $R$. acetosa. Besides, comparative analysis of genomic structure of $C$. mongolicum and other three Polygonaceae species was conducted, revealing more divergence in LSC and SSC regions than IR regions, also more divergence in IGSs than coding regions, and these divergent regions could be treated as mutational hotspots. Furthermore, expansions and contractions at SSC/IRs and LSC/IRs junctions were also analyzed. A total of 50 long repeats and 244 SSRs were identified. The adaptation evolution analysis showed that only $p s b K$ gene was positively selected, thus $p s b K$ might play a crucial role in the adaptation of Polygonaceae species. In summary, our results would lay a vigorous foundation for further study on molecular marker exploration, phylogenetic signature, and population studies in Calligonum species.

\section{Abbreviations}


CDS: Coding sequences; LSC:Large single copy; SSC:Small single copy; IR:Inverted repeat; Cp:Chloroplast; A:Adenine; T:Thymine; C:Cytosine; G:Guanine; SCU:Synonymous codon usage; RSCU:Relative synonymous codon usage; ENC:Effective number of codons; IGS:Intergenic spaces; SSR:Simple sequence repeat; $A_{3}$ :Adenine content at the third position of synonymous codons; $T_{3}:$ Thymine content at the third position of synonymous codons; $\mathrm{C}_{3}$ :Cytosine content at the third position of synonymous codons; $\mathrm{G}_{3}$ :Guanine content at the third position of synonymous codons; $\mathrm{GC}_{12}$ :Average $\mathrm{G}+\mathrm{C}$ content at the first and second positions of synonymous codons; $\mathrm{GC}_{3}: \mathrm{G}+\mathrm{C}$ content at the third positions of synonymous codons; $\mathrm{GC}_{3 s}: \mathrm{G}+\mathrm{C}$ frequencies of at the third positions of synonymous codons; PR2:Parity rule 2.

\section{Declarations}

\section{Ethics approval and consent to participate}

Not applicable.

\section{Consent for publish}

Not applicable.

\section{Competing interests}

The authors declare that they have no competing interests.

\section{Funding}

This research was funded by the National Science Foundation of China (31700338), the Science and Technology Innovation Program of Lanzhou Institute of Husbandry and Pharmaceutical Science, Chinese Academy of Agricultural Sciences (CAAS-LMY-04), the Innovation Project of Chinese Academy of Agricultural Sciences (CAAS-XTCX2016011-02), the Central Public-interest Scientific Institution Basal Research Fund (1610322019012), and the Gansu Provincial Science and Technology Major Projects (19ZD2NA002). None of the funding bodies have any role in the design of the study or collection, analysis, and interpretation of data as well as in writing the manuscript.

\section{Author Contributions}

D. H. R. and C. G. X. designed the experiments. Z. Q. and Y. H. S. performed the experiments. T. F. P., H. Y. and W. C. M. analyzed the sequencing data. D. H. R. wrote the paper. L. Y., Y. H. J. and C. G. X. revised this paper. All authors have read and approved the manuscript.

\section{Availability of data and materials}

The raw sequence data of $C$. mongolicum $\mathrm{cp}$ genome have been submitted to GenBank under accession number MT568767. The address is as follows: https://www.ncbi.nlm.nih.gov/genbank. 


\section{References}

1. Ren J, Tao L, Liu XM. Effect of sand burial depth on seed germination and seedling emergence of Calligonum L. species. J Arid Environ. 2002;51:603-11.

2. Ren J, Tao L. Effects of different pre-sowing seed treatments on germination of 10 Calligonum species. Forest Ecol Manag. 2004;195:291-300.

3. Mao ZM, Pan BR. The classification and distribution of Calligonum spp in China. Acta Phytotaxon Sin. 1986;24:98-107. (in Chinese).

4. Mao ZM. Flora of China. Vol. 25. Beijing: Beijing Science Press, China; 1998. pp. 120-33.

5. Wen ZB, Li Y, Zhang HX, Meng HH, Feng Y, Shi W. Species-level phylogeographical history of the endemic species Calligonum roborovskii and its close relatives in Calligonum section Medusa (Polygonaceae) in arid north-western China. Bot J Linn Soc. 2016;180:542-53.

6. Shi W, Pan BR, Gaskin JF, Kang XS. Morphological variation and chromosome studies in Calligonum mongolicum and $C$. pumilum (Polygonaceae) suggests the presence of only one species. Nord J Bot. 2009;27:81-5.

7. Fan $B L$, McHugh AD, Guo SJ, Ma QL, Zhang JH, Zhang XJ, et al. Factors influencing the natural regeneration of the pioneering shrub Calligonum mongolicum in sand dune stabilization plantations in arid deserts of northwest China. Ecol Evol. 2018;8:2975-84.

8. Zhang Q, Zhu XT. Microsatellite DNA loci from the drought desert plant Calligonum mongolicum Turcz. (Polygonaceae). Conserv Genet. 2009;10:1891-93.

9. Fan BL, Zhou YF, Ma QL, Yu QS, Zhao CM. Sun K. The bet-hedging strategies for seedling emergence of Calligonum mongolicum to adapt to the extreme desert environments in Northwestern China. Front Plant Sci. 2018;9:1167.

10. Liu N, Feng Y, Guan KY, Fan YQ, Chen JJ. Geographic distribution of Calligonum mongolicum. Arid Zone Res. 2015;32:753-59.

11. Jansen RK, Cai ZQ, Raubeson LA, Daniell H, dePamphilis CW, Leebens-Mack J, et al. Analysis of 81 genes from 64 plastid genomes resolves relationships in angiosperms and identifies genome-scale evolutionary patterns. Proc Natl Acad Sci USA. 2007;104:19369-74.

12. Xue S, Shi T, Luo WJ, Ni XP, Iqbal S, Ni ZJ, et al. Comparative analysis of the complete chloroplast genome among Prunus mume, P. armeniaca, and P. salicina. Hortic Res. 2019;6:89.

13. Raubeson LA, Peery R, Chumley TW, Dziubek C, Fourcade HM, Boore JL, et al. Comparative chloroplast genomics: analyses including new sequences from the angiosperms Nuphar advena and Ranunculus macranthus. BMC Genom. 2007;8:174.

14. Huang SN, Ge XJ, Cano A, Salazar BG, Deng YF. Comparative analysis of chloroplast genomes for five Dicliptera species (Acanthaceae): molecular structure, phylogenetic relationships, and adaptive evolution. Peer J. 2020;8:e8450.

15. Yan C, Du J, Gao L, Li Y, Hou X. The complete chloroplast genome sequence of watercress (Nasturtium officinale R. Br.): genome organization, adaptive evolution and phylogenetic 
relationships in Cardamineae. Gene. 2019;699:24-36.

16. Du XY, Zeng T, Feng Q, Hu LJ, Luo X, Weng QB, et al. The complete chloroplast genome sequence of yellow mustard (Sinapisalba L.) and its phylogenetic relationship to other Brassicaceae species. Gene. 2020;731:144340.

17. Gao C, Deng Y, Wang J. The complete chloroplast genomes of Echinacanthus species (Acanthaceae): phylogenetic relationships, adaptive evolution, and screening of molecular markers. Front Plant Sci. 2019;9:1989.

18. Wicke S, Schneeweiss GM, DePamphilis CW, Müller KF, Quandt D. The evolution of the plastid chromosome in land plants: gene content, gene order, gene function. Plant Mol Biol. 2011;76:27397.

19. Daniell H, Lin CS, Yu M, Chang WJ. Chloroplast genomes: diversity, evolution, and applications in genetic engineering. Genome Biol. 2016;17:134.

20. Jansen RK, Raubeson LA, Boore JL, Depamphilis CW, Chumley TW, Haberle RC, et al. Methods for obtaining and analyzing whole chloroplast genome sequences. Method Enzymol. 2005;395:348.

21. Tao XL, Ma LC, Zhang ZS, Liu WX, Liu ZP. Characterization of the complete chloroplast genome of alfalfa (Medicago sativa) (Leguminosae). Gene Reports. 2017;6:67-73.

22. Wakasugi T, Tsudzuki J, Ito S, Nakashima K, Tsudzuki T, Sugiura M. Loss of all ndh genes as determined by sequencing the entire chloroplast genome of the black pine Pinus thunbergii. Proc Natl Acad Sci USA. 1994;91:9794-98.

23. Kato T, Kaneko T, Sato S, Nakamura Y, Tabata S. Complete structure of the chloroplast genome of a legume, Lotus japonicas. DNA Res. 2000;7:323-30.

24. Shinozaki K, Ohme M, Tanaka M, Wakasugi T, Hayashida N, Matsubayashi T, et al. The complete nucleotide sequence of the tobacco chloroplast genome: its gene organization and expression. EMBO J. 1986;5:2043-49.

25. Wang RJ, Cheng CL, Chang CC, Wu CL, Su TM, Chaw SM. Dynamics and evolution of the inverted repeat-large single copy junctions in the chloroplast genomes of monocots. BMC Evol Biol. 2008;8:36.

26. Doyle JJ, Doyle JL. A rapid DNA isolation procedure for small quantities of fresh leaf tissue. Phytochem Bull. 1987;19:11-5.

27. Tillich M, Lehwark P, Pellizzer T, Ulbricht-Jones ES, Fischer A, Bock R, et al. GeSeq-versatile and accurate annotation of organelle genomes. Nucleic Acids Res. 2017;45:W6-11.

28. Lohse M, Drechsel O, Kahlau S, Bock R. 2013. Organellar Genome DRAW- a suite of tools for generating physical maps of plastid and mitochondrial genomes and visualizing expression data sets. Nucleic Acids Res. 2013; W575-81.

29. Zhang YY, Shi E, Yang ZP, Geng QF, Qiu YX, Wang ZS. Development and application of genomic resources in an endangered palaeoendemic tree, Parrotia subaequalis (Hamamelidaceae) from eastern China. Front Plant Sci. 2018;9:246. 
30. Gupta SK, Bhattacharyya TK, Ghosh TC. SCU in Lactococcus lactis: mutational bias versus translational selection. J Biomol Struct Dyn. 2004;21:527-36.

31. Guan DL, Ma LB, Khan MS, Zhang XX, Xu SQ, Xie JY. Analysis of codon usage patterns in Hirudinaria manillensis reveals a preference for GC-ending codons caused by dominant selection constraints. BMC Genom. 2018;19:542.

32. Sueoka N. Near homogeneity of PR2-bias fingerprints in the human genome and their implications in phylogenetic analyses. J Mol Evol. 2001;53:469-76.

33. Wright F. The 'effective number of codons' used in a gene. Gene. 1990;87:23-9.

34. Wei L, He J, Jia X, Qi Q, Liang ZS, Zheng H, et al. Analysis of codon usage bias of mitochondrial genome in Bombyx mori and its relation to evolution. BMC Evol Biol. 2014;14:262.

35. Thiel T, Michalek W, Varshney R, Graner A. Exploiting EST databases for the development and characterization of gene-derived SSR-markers in barley (Hordeum vulgare L.). Theor Appl Genet. 2003;106:411-22.

36. Poliakov A, Foong J, Brudno M, Dubchak I. Genome VISTA-an integrated software package for wholegenome alignment and visualization. Bioinformatics. 2014;30:2654-55.

37. Amiryousefi A, Hyvönen J, Poczai P. IRscope: an online program to visualize the junction sites of chloroplast genomes. Bioinformatics. 2018;34:3030-31.

38. Li L, Stoeckert CJ, Roos DS. OrthoMCL: identification of ortholog groups for eukaryotic genomes. Genome Res. 2003;13:2178-89.

39. Katoh K, Standley DM. MAFFT multiple sequence alignment software version 7: improvements in performance and usability. Molecular Biol Evol. 2013;30:772-80.

40. Yang ZH. PAML 4: phylogenetic analysis by maximum likelihood. Molecular Biol Evol. 2007;24:1586-91.

41. Wang XM, Zhou T, Bai GQ, Zhao YM. Complete chloroplast genome sequence of Fagopyrum dibotrys: genome features, comparative analysis and phylogenetic relationships. Sci Rep. 2018;8:12379.

42. Li X, Li YF, Zang MY, Li MZ, Fang YM. Complete chloroplast genome sequence and phylogenetic analysis of Quercus acutissima. Int J Mol Sci. 2018;19:2443.

43. Oldenburg DJ, Bendich AJ. The linear plastid chromosomes of maize: terminal sequences, structures, and implications for DNA replication. Curr Genet. 2016;62:431-42.

44. Cui GX, Wang CM, Wei XX, Yang HS, Lu Y, Wang XL, et al. Analysis of synonymous codon usage of the complete chloroplast genome in Phleum pretense cv. Minshan. Int J Agric Boil. 2020;24:352-58.

45. Funk H, Berg S, Krupinska K, Maier UG, Krause K. Complete DNA sequences of the plastid genomes of two parasitic flowering plant species, Cuscuta reflexa and Cuscuta gronovii. BMC Plant Bio. 2007;7:45.

46. Wu ZH, Gui ST, Quan ZW, Pan L, Wang SZ, Ke WD, et al. A precise chloroplast genome of Nelumbo nucifera (Nelumbonaceae) evaluated with Sanger, Illumina MiSeq, and PacBio RS II sequencing 
platforms: insight into the plastid evolution of basal eudicots. BMC Plant Bio. 2014;14:289.

47. Jansen RK, Wojciechowski MF, Sanniyasi E, Lee SB, Daniell H. Complete plastid genome sequence of the chickpea (Cicer arietinum) and the phylogenetic distribution of rps12 and clpP intron losses among legumes (Leguminosae). Mol Phylogenet Evol. 2008;48:1204-17.

48. Ma J, Yang BX, Zhu W, Sun LL, Tian JK, Wang XM. The complete chloroplast genome sequence of Mahonia bealei (Berberidaceae) reveals a significant expansion of the inverted repeat and phylogenetic relationship with other angiosperms. Gene. 2013;528:120-31.

49. Saski C, Lee SB, Fjellheim S, Guda C, Jansen RK, Luo H, et al. Complete chloroplast genome sequences of Hordeum vulgare, Sorghum bicolor and Agrostis stolonifera, and comparative analyses with other grass genomes. Theor Appl Genet. 2007;115:571-90.

50. Karumathil S, Raveendran NT, Ganesh D, Kumar NS, Nair RR, Dirisala VR. Evolution of SCU bias in West African and Central African strains of monkeypox virus. Evol Bioinform. 2018;14:1-22.

51. Liu HM, He R, Zhang HY, Huang YB, Tian ML, Zhang JJ. Analysis of SCU in Zea mays. Mol Biol Rep. 2010;37:677-84.

52. Wang LY, Xing HX, Yuan YC, Wang XL, Saeed M, Tao JC, et al. Genome-wide analysis of codon usage bias in four sequenced cotton species. Plos One. 2018;13:e0194372.

53. Qiu S, Zeng K, Slotte T, Wright S, Charlesworth D. Reduced efficacy of natural selection on codon usage bias in selfing Arabidopsis and Capsella species. Genome Biol Evol. 2011;3:868-80.

54. Li GL, Pan ZL, Gao SC, He YY, Xia QY, Yan J, et al. Analysis of synonymous codon usage of chloroplast genome in Porphyra umbilicalis. Genes Genom. 2019;41:1173-81.

55. Sueoka N. Directional mutation pressure and neutral molecular evolution. P Natl Acad Sci USA. 1988;85:2653-57.

56. Zhang DS, Hu P, Liu TG, Wang J, Jiang SW, Xu QH, et al. GC bias lead to increased small amino acids and random coils of proteins in coldwater fishes. BMC Genom. 2018;19:315.

57. Nie XJ, Lv SZ, Zhang YX, Du XH, Wang L, Biradar SS, et al. Complete chloroplast genome sequence of a major invasive species, crofton weed (Ageratina adenophora). PLoS One. 2012;7:e36869.

58. Wang CL, Ding MQ, Zou CY, Zhu XM, Tang Y, Zhou ML, et al. Comparative analysis of four buckwheat species based on morphology and complete chloroplast genome sequences. Sci Rep. 2017;7:6514.

59. Chen N, Sha LN, Dong ZZ, Tang C, Wang Y, Kang HY, et al. Complete structure and variation of the chloroplast genome of Agropyron cristatum (L.) Gaertn. Gene. 2018;640:86-96.

60. Shingo K, Jocelyn B, Minako H, Yoshino H, Maya O, Midori I, et al. Uncovering the protein translocon at the chloroplast inner envelope membrane. Science. 2013;339:571-74.

61. George B, Bhatt BS, Awasthi M, George B, Singh AK. Comparative analysis of microsatellites in chloroplast genomes of lower and higher plants. Curr Genet. 2015;61:665-77.

62. Ebert D, Peakall R. Chloroplast simple sequence repeats (cpSSRs): technical resources and recommendations for expandingcp SSR discovery and applications to a wide array of plant species. Mol Ecol Resour. 2009;9:673-90. 
63. Yamane K, Lü N, Ohnishi O. Multiple origins and high genetic diversity of cultivated radish inferred from polymorphism in chloroplast simple sequence repeats. Breed Sci. 2009;59:55-65.

64. Lee SL, Nkongolo K, Park D, Choi IY, Choi AY, Kim NS. Characterization of chloroplast genomes of Alnusrubra and Betulacordifolia, and their use in phylogenetic analyses in Betulaceae. Genes Genom. 2019;41:305-16.

65. Lemieux C, Otis C, Turmel M. Ancestral chloroplast genome in Mesostigma viride reveals an early branch of green plant evolution. Nature. 2000;403:649-52.

66. Chang CC, Lin HC, Lin IP, Chow TY, Chen HH, Chen WH, et al. The chloroplast genome of Phalaenopsis aphrodite(Orchidaceae): comparative analysis of evolutionary rate with that of grasses and its phylogenetic implications. Mol Biol Evol. 2005;23:279-91.

67. Choi KS, Park SJ. The complete chloroplast genome sequence of Aster spathulifolius, (Asteraceae); genomic features and relationship with Asteraceae. Gene. 2015;572:214-21.

68. Li D, Zhao CH, Liu X. Complete chloroplast genome sequences of Kaempferia galangal and Kaempferia elegans: molecular structures and comparative analysis. Molecules. 2018;24:474.

69. Wang RJ, Cheng CL, Chang CC, Wu CL, Su TM, Chaw SM. Dynamics and evolution of the inverted repeat-large single copy junctions in the chloroplast genomes of monocots. BMC Evol Biol. 2008;8:36.

70. Scottphillips TC, Laland KN, Shuker DM, Dickins TE, West ST. The niche construction perspective: a critical appraisal. Evolution. 2013;68:1231-43.

71. Makalowski W, Boguski MS. Evolutionary parameters of the transcribed mammalian genome: an analysis of 2,820 orthologous rodent and human sequences. P Natl Acad Sci USA. 1998;95:940712.

\section{Tables}

Table 1. Bases composition of the C. mongolicum cp genome.

\begin{tabular}{|lllllll|}
\hline Region & $\mathrm{A}(\%)$ & $\mathrm{T}(\mathrm{U})(\%)$ & $\mathrm{C}(\%)$ & $\mathrm{G}(\%)$ & $\mathrm{A}+\mathrm{T}(\%)$ & $\mathrm{G}+\mathrm{C}(\%)$ \\
\hline LSC & 31.74 & 32.68 & 18.24 & 17.35 & 64.42 & 35.58 \\
\hline SSC & 35.78 & 31.73 & 17.08 & 15.41 & 67.51 & 32.49 \\
\hline IR & 29.33 & 29.33 & 20.67 & 20.67 & 58.66 & 41.34 \\
\hline Total & 31.16 & 31.34 & 19.06 & 18.44 & 62.5 & 37.5 \\
\hline
\end{tabular}

Table 2. The statistics of exons and introns in genes from C. mongolicum cp genome. 


\begin{tabular}{|c|c|c|c|c|c|c|}
\hline \multirow[t]{2}{*}{ Gene } & \multirow[t]{2}{*}{ Location } & \multicolumn{5}{|l|}{ Length } \\
\hline & & Exon I & Intron I & Exon II & Intron II & Exon III \\
\hline trnK-UUU & LSC & 35 & 2511 & 37 & & \\
\hline rps16 & LSC & 231 & 858 & 36 & & \\
\hline atpF & LSC & 411 & 758 & 144 & & \\
\hline rpoc1 & LSC & 1607 & 776 & 430 & & \\
\hline$y c f 3$ & LSC & 147 & 738 & 122 & 840 & 124 \\
\hline $\operatorname{trn} L-U A A$ & LSC & 35 & 520 & 50 & & \\
\hline $\operatorname{trn} V-U A C$ & LSC & 37 & 593 & 36 & & \\
\hline$c l p P$ & LSC & 270 & 633 & 292 & 1143 & 71 \\
\hline$r p / 2 \_1$ & IRa & 393 & 662 & 435 & & \\
\hline$n d h B_{-} 1$ & IRa & 777 & 679 & 756 & & \\
\hline rps12_1 & IRa & 25 & 533 & 232 & & \\
\hline trnI-GAU_1 & IRa & 37 & 944 & 35 & & \\
\hline $\operatorname{trn} A-U G C_{-} 1$ & IRa & 38 & 803 & 36 & & \\
\hline$n d h A$ & SSC & 537 & 1200 & 561 & & \\
\hline $\operatorname{trn} A-U G C \_2$ & IRb & 36 & 803 & 38 & & \\
\hline trnI-GAU_2 & IRb & 35 & 944 & 37 & & \\
\hline rps12_2 & IRb & 232 & 533 & 25 & & \\
\hline$n d h B \_2$ & IRb & 756 & 679 & 777 & & \\
\hline rp/2_2 & IRb & 435 & 662 & 393 & & \\
\hline
\end{tabular}

Table 3. Codon usage and high frequency used codons in C. mongolicum cp genome. The highest frequency used codons (RSCU values $>1.3$ ) are in bold. RSCU: relative synonymous codon usage. 


\begin{tabular}{|c|c|c|c|c|c|c|c|}
\hline Amino acid & Condon & Number & RSCU & Amino acid & Condon & Number & RSCU \\
\hline \multirow[t]{4}{*}{ Ala(A) } & GCT & 497 & 1.72 & $\operatorname{Asn}(\mathrm{N})$ & AAT & 722 & 1.56 \\
\hline & GCC & 208 & 0.72 & & AAC & 202 & 0.44 \\
\hline & GCA & 324 & 1.12 & Pro(P) & ССT & 350 & 1.6 \\
\hline & GCG & 130 & 0.45 & & $\mathrm{CCC}$ & 167 & 0.76 \\
\hline \multirow[t]{2}{*}{ Cys(C) } & TGT & 160 & 1.45 & & $\mathrm{CCA}$ & 239 & 1.09 \\
\hline & TGC & 61 & 0.55 & & CCG & 120 & 0.55 \\
\hline \multirow[t]{2}{*}{ Asp(D) } & GAT & 654 & 1.57 & $\mathrm{G} \ln (\mathrm{Q})$ & CAA & 552 & 1.49 \\
\hline & GAC & 181 & 0.43 & & CAG & 187 & 0.51 \\
\hline \multirow[t]{2}{*}{ Glu(E) } & GAA & 832 & 1.48 & $\operatorname{Arg}(R)$ & CGT & 298 & 1.43 \\
\hline & GAG & 290 & 0.52 & & CGC & 68 & 0.33 \\
\hline \multirow[t]{2}{*}{ Phe(F) } & TTT & 765 & 1.34 & & CGA & 310 & 1.48 \\
\hline & TTC & 374 & 0.66 & & CGG & 85 & 0.41 \\
\hline \multirow[t]{4}{*}{ Gly(G) } & GGT & 441 & 1.23 & & AGA & 338 & 1.62 \\
\hline & GGC & 182 & 0.51 & & AGG & 155 & 0.74 \\
\hline & GGA & 561 & 1.57 & Ser(S) & TCT & 415 & 1.68 \\
\hline & GGG & 248 & 0.69 & & TCC & 232 & 0.94 \\
\hline \multirow[t]{2}{*}{$\operatorname{His}(\mathrm{H})$} & CAT & 380 & 1.53 & & TCA & 290 & 1.17 \\
\hline & CAC & 118 & 0.47 & & TCG & 134 & 0.54 \\
\hline \multirow[t]{3}{*}{$\| \mathrm{ll}(\mathrm{I})$} & ATT & 875 & 1.52 & & AGT & 305 & 1.23 \\
\hline & ATC & 323 & 0.56 & & $A G C$ & 106 & 0.43 \\
\hline & ATA & 525 & 0.91 & $\operatorname{Thr}(\mathrm{T})$ & ACT & 397 & 1.56 \\
\hline \multirow[t]{2}{*}{ Lys(K) } & AAA & 818 & 1.51 & & ACC & 191 & 0.75 \\
\hline & AAG & 263 & 0.49 & & ACA & 316 & 1.24 \\
\hline \multirow[t]{5}{*}{ Leu(L) } & TTA & 696 & 1.92 & & ACG & 115 & 0.45 \\
\hline & TTG & 453 & 1.25 & $\operatorname{Val}(\mathrm{V})$ & GTT & 422 & 1.49 \\
\hline & CTT & 455 & 1.26 & & GTC & 147 & 0.52 \\
\hline & СTC & 133 & 0.37 & & GTA & 414 & 1.46 \\
\hline & CTA & 303 & 0.84 & & GTG & 150 & 0.53 \\
\hline
\end{tabular}




\begin{tabular}{|llllllll|} 
& CTG & 135 & 0.37 & $\operatorname{Tyr}(\mathrm{Y})$ & TAT & 609 & 1.6 \\
$\operatorname{Met}(\mathrm{M})$ & ATG & 474 & 1 & & TAC & 151 & 0.4 \\
$\operatorname{Trp}(\mathrm{W})$ & TGG & 383 & 1 & & & & \\
\hline
\end{tabular}

Table 4. Long repeat sequences in the $\mathrm{C}$. mongolicum cp genome. F, forward; R, reverse; IGS, intergenic space. 


\begin{tabular}{|c|c|c|c|c|c|c|c|c|}
\hline ID & $\begin{array}{l}\text { Repeat } \\
\text { start } 1\end{array}$ & Type & $\begin{array}{l}\text { Size } \\
\text { (bp) }\end{array}$ & $\begin{array}{l}\text { Repeat } \\
\text { start } 2\end{array}$ & Mismatch(bp) & $\begin{array}{l}\text { E- } \\
\text { Value }\end{array}$ & Gene & Region \\
\hline 1 & 101960 & $F$ & 42 & 128315 & 0 & $\begin{array}{l}3.82 \mathrm{E}- \\
16\end{array}$ & IGS, ndhA & $\begin{array}{l}\text { IRa, } \\
\text { SSC, }\end{array}$ \\
\hline 2 & 114286 & $F$ & 45 & 114298 & -3 & $\begin{array}{l}2.29 \mathrm{E}- \\
12\end{array}$ & $y c f 1$ & IRa \\
\hline 3 & 135499 & $F$ & 45 & 135511 & -3 & $\begin{array}{l}2.29 \mathrm{E}- \\
12\end{array}$ & $y c f 1$ & IRb \\
\hline 4 & 70628 & $\mathrm{~F}$ & 38 & 115967 & -1 & $\begin{array}{l}1.12 \mathrm{E}- \\
11\end{array}$ & IGS, ycf1 & $\begin{array}{l}\text { LSC, } \\
\text { IRa }\end{array}$ \\
\hline 5 & 45870 & $F$ & 39 & 101962 & -2 & $\begin{array}{l}1.63 \mathrm{E}- \\
10\end{array}$ & $y c f 3$, IGS & $\begin{array}{l}\text { SSC, } \\
\text { IRa }\end{array}$ \\
\hline 6 & 45870 & $F$ & 39 & 128317 & -2 & $\begin{array}{l}1.63 \mathrm{E}- \\
10\end{array}$ & $y c f 3, n d h A$ & $\begin{array}{l}\text { LSC, } \\
\text { SSC }\end{array}$ \\
\hline 7 & 89639 & $\mathrm{~F}$ & 39 & 89682 & -2 & $\begin{array}{l}1.63 \mathrm{E}- \\
10\end{array}$ & IGS & IRa \\
\hline 8 & 89646 & $\mathrm{~F}$ & 32 & 89689 & 0 & $\begin{array}{l}4.01 \mathrm{E}- \\
10\end{array}$ & IGS & IRa \\
\hline 9 & 160121 & $\mathrm{~F}$ & 32 & 160164 & 0 & $\begin{array}{l}4.01 \mathrm{E}- \\
10\end{array}$ & IGS & IRb \\
\hline 10 & 114296 & $\mathrm{~F}$ & 35 & 114308 & -2 & $\begin{array}{l}3.35 \mathrm{E}- \\
08\end{array}$ & $y c f 1$ & IRa \\
\hline 11 & 128532 & $\mathrm{~F}$ & 28 & 128561 & 0 & $\begin{array}{l}1.03 \mathrm{E}- \\
07\end{array}$ & $n d h A$ & SSC \\
\hline 12 & 28584 & $\mathrm{R}$ & 34 & 28584 & -2 & $\begin{array}{l}1.26 \mathrm{E}- \\
07\end{array}$ & IGS & LSC \\
\hline 13 & 110672 & $\mathrm{~F}$ & 34 & 110704 & -2 & $\begin{array}{l}1.26 \mathrm{E}- \\
07\end{array}$ & IGS & IRa \\
\hline 14 & 139104 & $\mathrm{~F}$ & 34 & 139136 & -2 & $\begin{array}{l}1.26 \mathrm{E}- \\
07\end{array}$ & IGS & IRb \\
\hline 15 & 112364 & $\mathrm{~F}$ & 31 & 112392 & -1 & $\begin{array}{l}1.49 \mathrm{E}- \\
07\end{array}$ & IGS & IRa \\
\hline 16 & 137419 & $\mathrm{~F}$ & 31 & 137447 & -1 & $\begin{array}{l}1.49 \mathrm{E}- \\
07\end{array}$ & IGS & IRb \\
\hline 17 & 52182 & $\mathrm{~F}$ & 27 & 52196 & 0 & $\begin{array}{l}4.10 \mathrm{E}- \\
07\end{array}$ & IGS & LSC \\
\hline 18 & 29564 & $F$ & 30 & 29580 & -1 & $\begin{array}{l}5.77 \mathrm{E}- \\
07\end{array}$ & IGS & LSC \\
\hline
\end{tabular}




\begin{tabular}{|c|c|c|c|c|c|c|c|c|}
\hline 19 & 113225 & $\mathrm{~F}$ & 35 & 113246 & -3 & $\begin{array}{l}1.11 \mathrm{E}- \\
06\end{array}$ & $y c f 1$ & IRa \\
\hline 20 & 136561 & $\mathrm{~F}$ & 35 & 136582 & -3 & $\begin{array}{l}1.11 \mathrm{E}- \\
06\end{array}$ & $y c f 1$ & $\mathrm{IRb}$ \\
\hline 21 & 40309 & $\mathrm{~F}$ & 26 & 42524 & 0 & $\begin{array}{l}1.64 \mathrm{E}- \\
06\end{array}$ & $p s a B, p s a A$ & LSC \\
\hline 22 & 113217 & $\mathrm{~F}$ & 34 & 113238 & -3 & $\begin{array}{l}4.05 \mathrm{E}- \\
06\end{array}$ & $y c f 1$ & IRa \\
\hline 23 & 136570 & $\mathrm{~F}$ & 34 & 136591 & -3 & $\begin{array}{l}4.05 \mathrm{E}- \\
06\end{array}$ & $y c f 1$ & $\mathrm{IRb}$ \\
\hline 24 & 40007 & $\mathrm{~F}$ & 28 & 42243 & -1 & $\begin{array}{l}8.62 \mathrm{E}- \\
06\end{array}$ & $p s a B, p s a A$ & LSC \\
\hline 25 & 45882 & $\mathrm{~F}$ & 27 & 101974 & -1 & $\begin{array}{l}3.32 \mathrm{E}- \\
05\end{array}$ & $y c f 3$, IGS & $\begin{array}{l}\text { LSC, } \\
\text { IRa }\end{array}$ \\
\hline 26 & 45882 & $\mathrm{~F}$ & 27 & 128329 & -1 & $\begin{array}{l}3.32 \mathrm{E}- \\
05\end{array}$ & $y c f 3, n d h A$ & $\begin{array}{l}\text { LSC, } \\
\text { SSC }\end{array}$ \\
\hline 27 & 4793 & $F$ & 32 & 121628 & -3 & $\begin{array}{l}5.37 \mathrm{E}- \\
05\end{array}$ & IGS & $\begin{array}{l}\text { LSC, } \\
\text { SSC }\end{array}$ \\
\hline 28 & 8935 & $\mathrm{~F}$ & 29 & 37672 & -2 & $\begin{array}{l}9.37 \mathrm{E}- \\
05\end{array}$ & $\begin{array}{l}\operatorname{trnS}-G C U, \\
\operatorname{trnS}-U G A\end{array}$ & LSC \\
\hline 29 & 114310 & $\mathrm{~F}$ & 29 & 114322 & -2 & $\begin{array}{l}9.37 \mathrm{E}- \\
05\end{array}$ & $y c f 1$ & IRa \\
\hline 30 & 135491 & $\mathrm{~F}$ & 29 & 135503 & -2 & $\begin{array}{l}9.37 \mathrm{E}- \\
05\end{array}$ & $y c f 1$ & $\mathrm{IRb}$ \\
\hline 31 & 29571 & $\mathrm{~F}$ & 23 & 29587 & 0 & $\begin{array}{l}1.05 \mathrm{E}- \\
04\end{array}$ & IGS & LSC \\
\hline 32 & 52185 & $\mathrm{~F}$ & 26 & 52215 & -1 & $\begin{array}{l}1.28 \mathrm{E}- \\
04\end{array}$ & IGS & LSC \\
\hline 33 & 40858 & $\mathrm{~F}$ & 31 & 43082 & -3 & $\begin{array}{l}1.95 \mathrm{E}- \\
04\end{array}$ & $p s a B, p s a A$ & LSC \\
\hline 34 & 10845 & $\mathrm{~F}$ & 25 & 38665 & -1 & $\begin{array}{l}4.92 \mathrm{E}- \\
04\end{array}$ & $\begin{array}{l}\text { IGS, trnG- } \\
\text { UCC }\end{array}$ & LSC \\
\hline 35 & 28587 & $\mathrm{~F}$ & 25 & 34468 & -1 & $\begin{array}{l}4.92 \mathrm{E}- \\
04\end{array}$ & IGS & LSC \\
\hline 36 & 112307 & $\mathrm{~F}$ & 25 & 112457 & -1 & $\begin{array}{l}4.92 \mathrm{E}- \\
04\end{array}$ & IGS & IRa \\
\hline 37 & 137360 & $\mathrm{~F}$ & 25 & 137510 & -1 & $\begin{array}{l}4.92 \mathrm{E}- \\
04\end{array}$ & IGS & $\mathrm{IRb}$ \\
\hline 38 & 113157 & $\mathrm{~F}$ & 30 & 136649 & -3 & $\begin{array}{l}7.03 \mathrm{E}- \\
04\end{array}$ & $y c f 1$ & $\begin{array}{l}\text { IRa, } \\
\text { IRb }\end{array}$ \\
\hline
\end{tabular}




\begin{tabular}{|c|c|c|c|c|c|c|c|c|}
\hline 39 & 113163 & $F$ & 30 & 136655 & -3 & $\begin{array}{l}7.03 \mathrm{E}- \\
04\end{array}$ & $y c f 1$ & $\begin{array}{l}\text { IRa, } \\
\text { IRb }\end{array}$ \\
\hline 40 & 30761 & $\mathrm{R}$ & 27 & 30761 & -2 & $\begin{array}{l}1.30 \mathrm{E}- \\
03\end{array}$ & IGS & LSC \\
\hline 41 & 136577 & $\mathrm{~F}$ & 27 & 136598 & -2 & $\begin{array}{l}1.30 \mathrm{E}- \\
03\end{array}$ & $y c f 1$ & IRb \\
\hline 42 & 38853 & $F$ & 21 & 69758 & 0 & $\begin{array}{l}1.68 \mathrm{E}- \\
03\end{array}$ & $\begin{array}{l}\text { IGS, trnP- } \\
\text { UGG }\end{array}$ & LSC \\
\hline 43 & 44430 & $\mathrm{R}$ & 21 & 50104 & 0 & $\begin{array}{l}1.68 \mathrm{E}- \\
03\end{array}$ & IGS & LSC \\
\hline 44 & 59741 & $\mathrm{R}$ & 21 & 59741 & 0 & $\begin{array}{l}1.68 \mathrm{E}- \\
03\end{array}$ & IGS & LSC \\
\hline 45 & 112374 & $\mathrm{~F}$ & 21 & 112402 & 0 & $\begin{array}{l}1.68 \mathrm{E}- \\
03\end{array}$ & IGS & IRa \\
\hline 46 & 139117 & $F$ & 21 & 139149 & 0 & $\begin{array}{l}1.68 \mathrm{E}- \\
03\end{array}$ & IGS & $\mathrm{IRb}$ \\
\hline 47 & 52199 & $F$ & 24 & 52215 & -1 & $\begin{array}{l}1.89 \mathrm{E}- \\
03\end{array}$ & IGS & LSC \\
\hline 48 & 7567 & $\mathrm{R}$ & 29 & 7572 & -3 & $\begin{array}{l}2.53 \mathrm{E}- \\
03\end{array}$ & IGS & LSC \\
\hline 49 & 15150 & $\mathrm{R}$ & 29 & 121615 & -3 & $\begin{array}{l}2.53 \mathrm{E}- \\
03\end{array}$ & IGS & $\begin{array}{l}\text { LSC, } \\
\text { SSC }\end{array}$ \\
\hline 50 & 114278 & $\mathrm{~F}$ & 29 & 114314 & -3 & $\begin{array}{l}2.53 \mathrm{E}- \\
03\end{array}$ & $y c f 1$ & IRa \\
\hline
\end{tabular}

Table 5. Summary of cp genome features of C. mongolicum and other three related plants species. 


\begin{tabular}{|lllll|}
\hline Genome features & $\begin{array}{l}\text { Calligonum } \\
\text { mongolicum }\end{array}$ & $\begin{array}{l}\text { Fagopyrum } \\
\text { esculentum }\end{array}$ & $\begin{array}{l}\text { Rheum } \\
\text { palmatum }\end{array}$ & $\begin{array}{l}\text { Rumex } \\
\text { acetosa }\end{array}$ \\
\hline Genome Size (bp) & 162,124 & 159,599 & 161,541 & 160,269 \\
\hline LSC length (bp) & 87,718 & 84,884 & 86,518 & 86,135 \\
\hline SSC length (bp) & 13,382 & 13,344 & 13,111 & 13,128 \\
\hline IR length (bp) & 30,512 & 30,685 & 30,956 & 30,503 \\
\hline Number of genes & 131 & 131 & 131 & 129 \\
\hline $\begin{array}{l}\text { Number of protein } \\
\text { coding genes }\end{array}$ & 78 & 72 & 81 & 67 \\
\hline Number of tRNA genes & 45 & 37 & 37 & 36 \\
\hline Number of rRNA genes & 8 & 8 & 8 & 8 \\
\hline
\end{tabular}

\section{Figures}




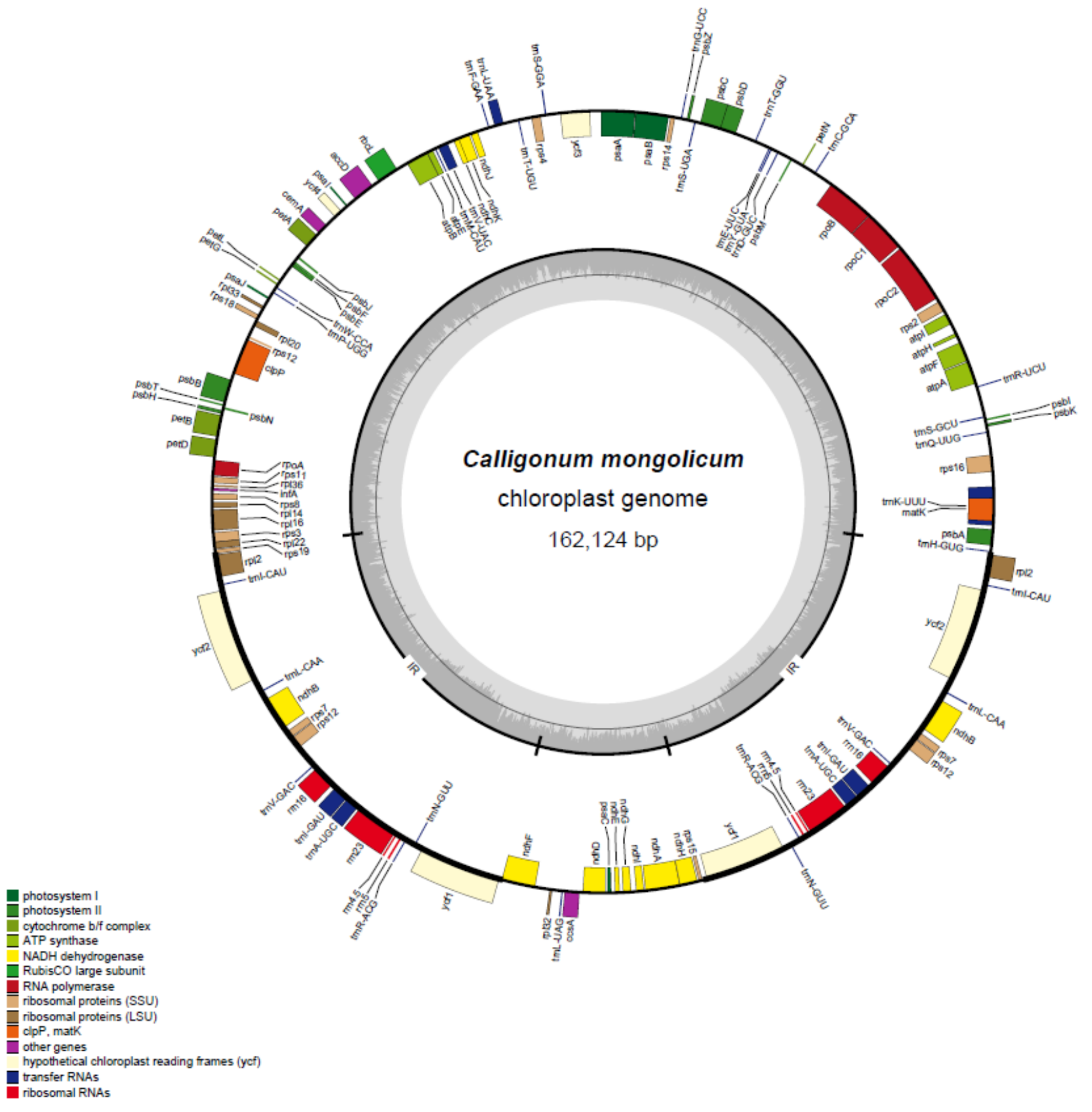

Figure 1

Cp genome map of C. mongolicum. Genes inside the circle and those outside are transcribed clockwise and counter-clockwise, respectively. Different colored flags show genes with different functions. The GC and AT content are represented by the darker gray and the lighter gray, respectively. 

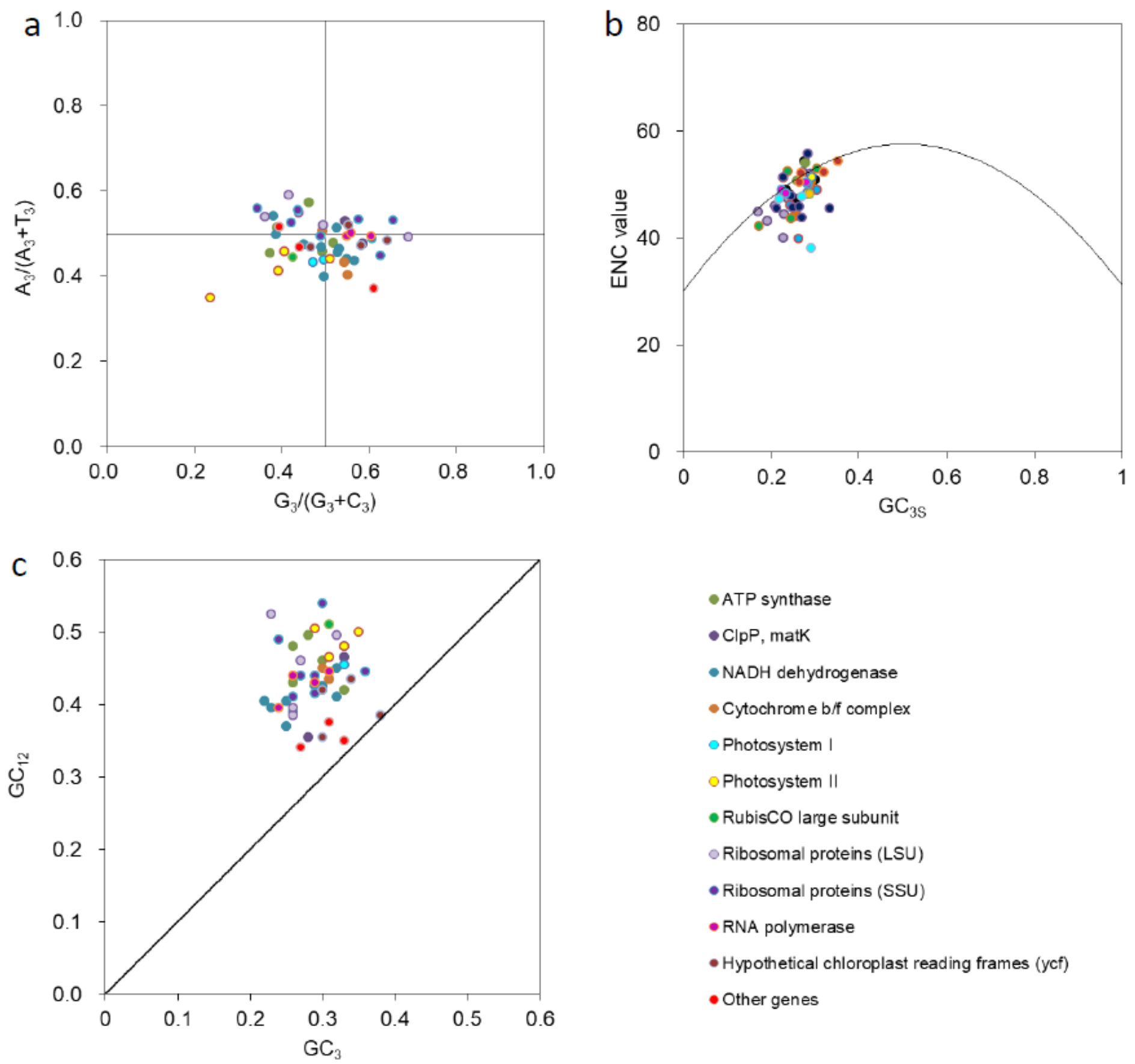

\section{Figure 2}

Multivariate statistical analysis for genes in C. mongolicum cp genome. a, PR2 analysis, A3, T3, C3 and G3 represents nucleotide A, T, C and G content at the third position of synonymous codons, respectively; b, ENC-plot analysis, ENC: effective number of codons. GC3s: the frequencies of nucleotide $\mathrm{G}+\mathrm{C}$ at the third position of codons. The expected relationship between ENC values and GC3s was reflected on the curve with random codon usage assumption; c, Neutrality plot analysis. GC12: the average content of nucleotide $\mathrm{G}+\mathrm{C}$ at the first and second positions of synonymous codons. GC3: the content of nucleotide 
$\mathrm{G}+\mathrm{C}$ at the third position of synonymous codons. The curve on the neutrality plot shows that the value of GC12 is equal to GC3.

a

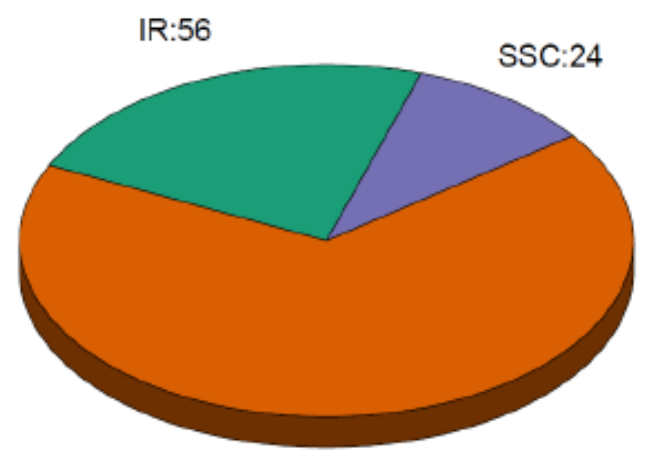

LSC:164 b

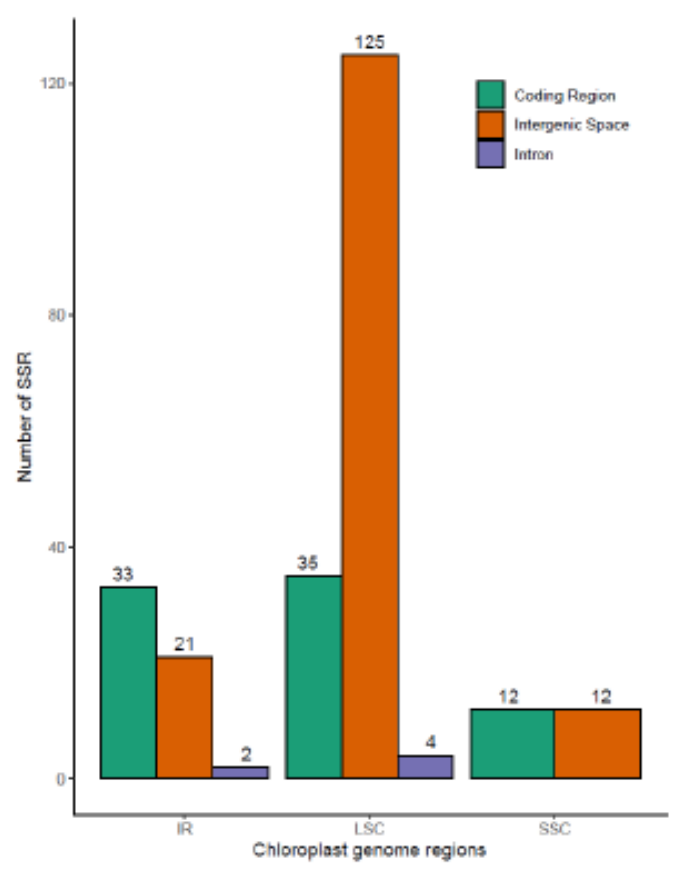

C

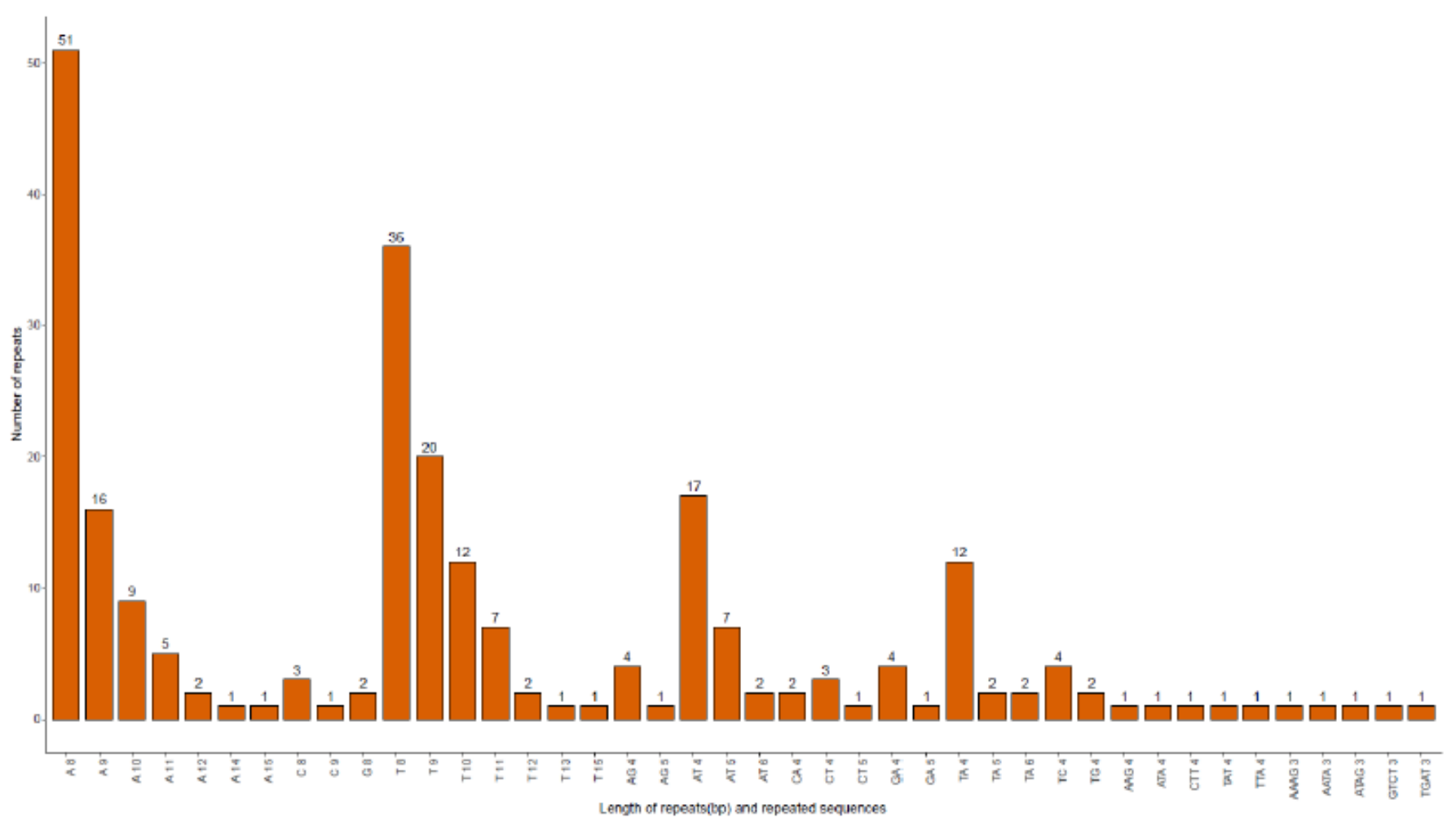

Figure 3

The simple sequence repeats (SSRs) in C. mongolicum cp genome. a, Distribution of SSRs in the LSC, SSC and IR regions; b, Presence of SSRs in the protein-coding regions, intergenic spaces (IGSs) and introns of LSC, SSC and IR regions; C, Types of nucleotides. 


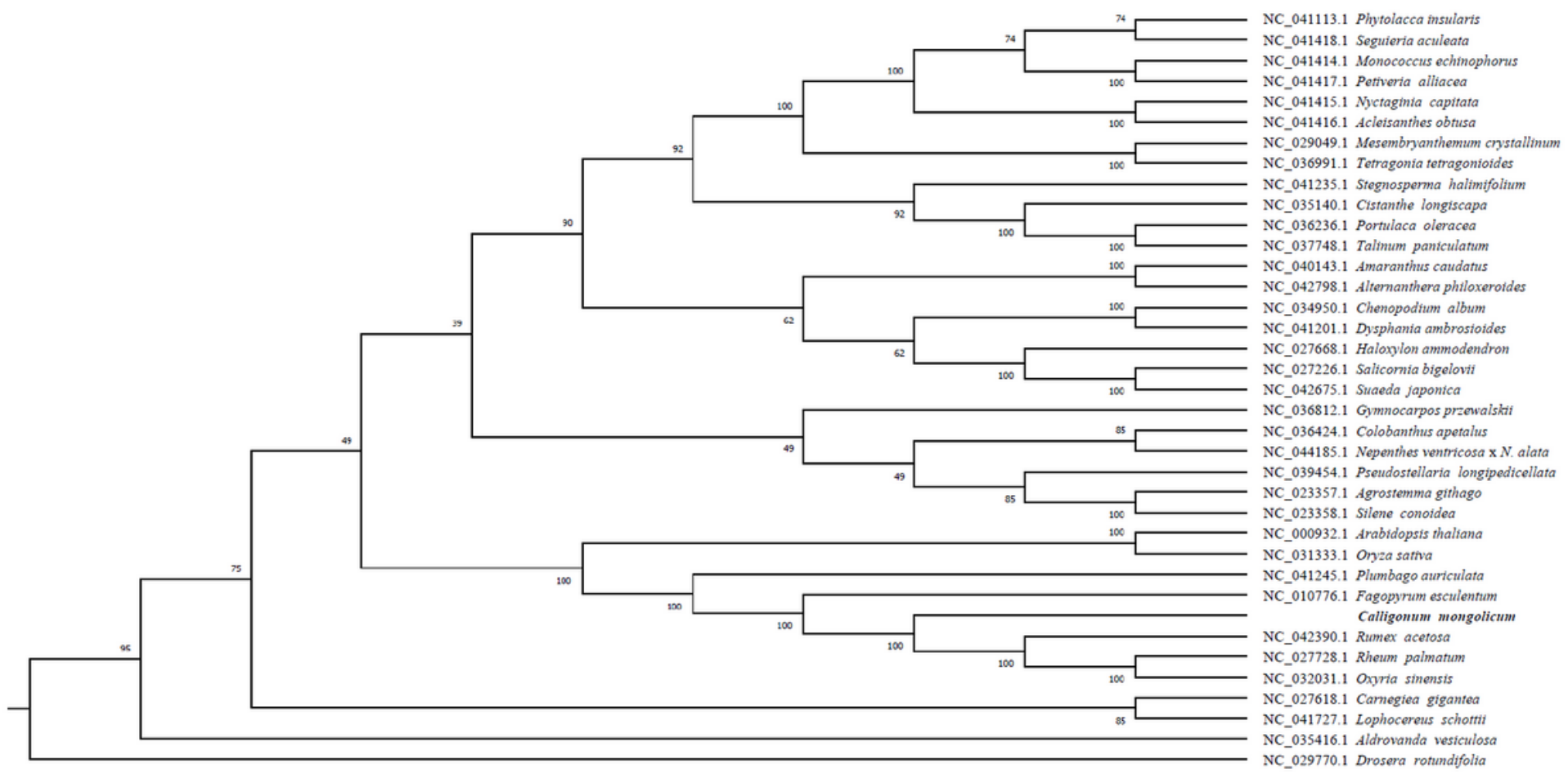

Figure 4

Phylogenetic relationship analysis of 37 species based on complete cp genomes. The phylogenetic tree was constructed by the neighbor-joining method. The bootstrap values were shown next to the branches based on 1000 replicates. The cp genome accession numbers from Genbank were labeled near to the names of plant species. C. mongolicum cp genome was in bold. 

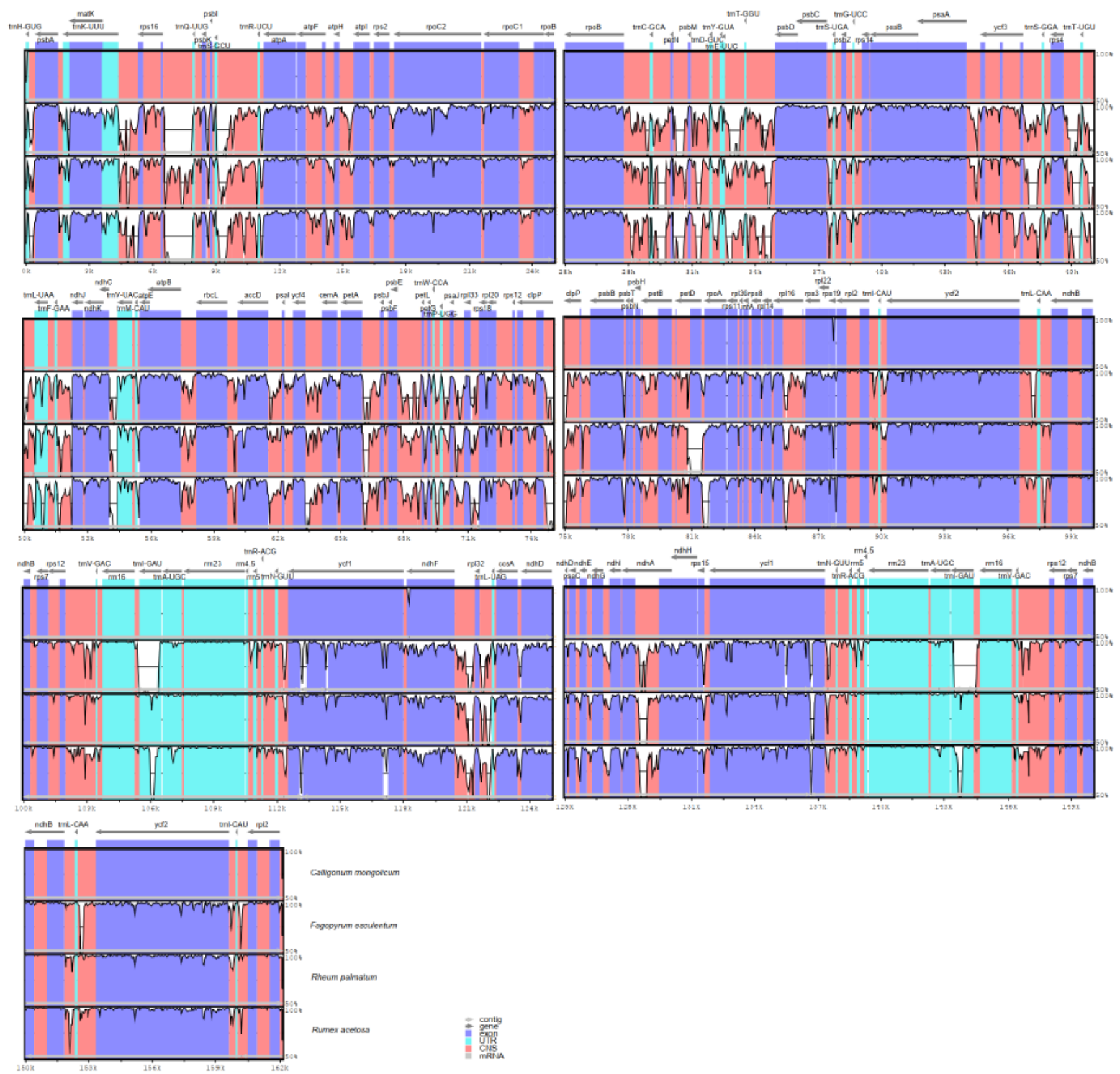

\section{Figure 5}

Complete $\mathrm{cp}$ genome comparison of $\mathrm{C}$. mongolicum and other three related plants species. The $\mathrm{cp}$ genome of $\mathrm{C}$. mongolicum was the reference and shown on the $\mathrm{X}$-axis. The gene's orientations were shown by the grey arrows combined thick black lines on the top of the alignment. The Y-axis denotes identity ranging from $50 \%$ to $100 \%$. UTR, untranslated regions. CNS, conserved non-coding sequences. 


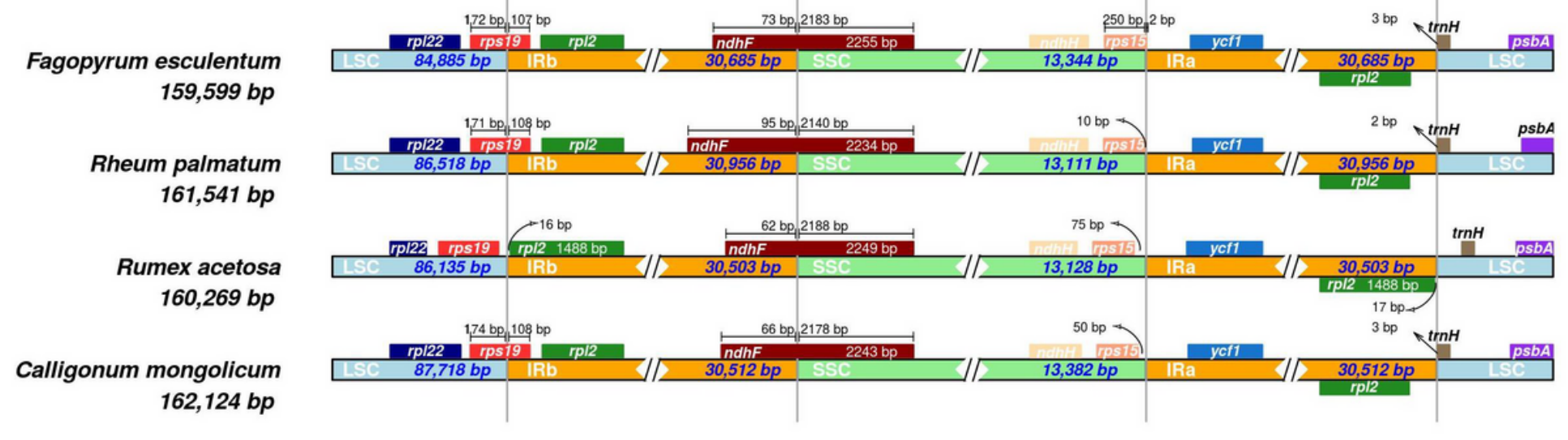

Figure 6

Comparison of junctions of the large single copy (LSC), small single copy (SSC), and inverted repeat (IR) in $\mathrm{cp}$ genomes of $\mathrm{C}$. mongolicum and other three related plant species. Genes and regions are devided by colored boxes. The base lengths (bp) represent the gaps between the genes and the borders. Extensions are displayed above the boxes. The lengths of the four regions are also shown in the box.

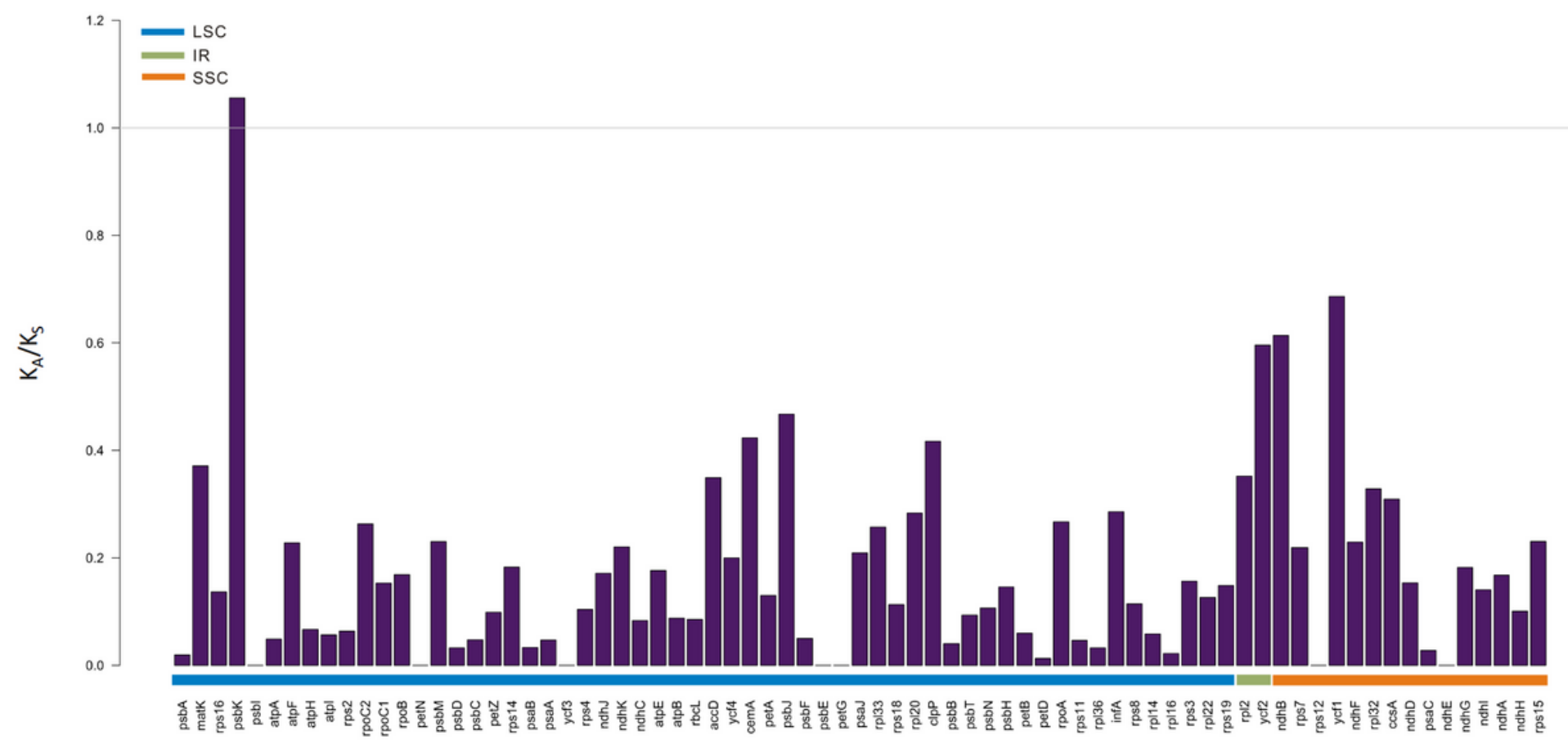

Figure 7

$\omega$ values among the five Polygonaceae species. $\omega$ value $=K A / K S . K A$, the nonsynonymous substitution rate. KS, the synonymous substitution rate. The region of gene distribution was shown in different color blocks.

\section{Supplementary Files}


This is a list of supplementary files associated with this preprint. Click to download.

- Supplementarylnformation.pdf 